\title{
Sensorless Control of Switched Reluctance Motor Drive with Fuzzy Logic Based Rotor Position Estimation
}

\author{
R. A. Gupta \\ Department of Electrical Engineering, \\ Malaviya National Institute of Technology, \\ Jaipur-302017, INDIA
}

\author{
S.K.Bishnoi \\ Department of Electrical Engineering, \\ Malaviya National Institute of Technology, \\ Jaipur-302017, INDIA
}

\author{
Rajesh Kumar \\ Department of Electrical Engineering, \\ Malaviya National Institute of Technology, \\ Jaipur-302017, INDIA
}

\begin{abstract}
This paper describes an accurate rotor position estimation, which is very important for high performance operation of Switched Reluctance Motor (SRM). Earlier, a rotor position sensor has been used for sensing the rotor position. The position sensor used in SRM drives have the disadvantages of additional cost, electrical connections, mechanical alignment problems, less suitability to space restricted applications and significant disadvantage of being inherent source of unreliability. These bottlenecks have been motivated for the development of several sensorless techniques in the recent years. Here, a proposed sensorless scheme based on fuzzy system is used to overcome the disadvantages of sensor scheme. The rotor position or angle can be estimated by using the unique relationship between flux linkage and phase current in term of fuzzy rule base. Both simulation and experiment results on a Digital Signal Processor (DSP) based real time drive are presented to show the effectiveness of this scheme. The proposed scheme is provided to demonstrate the validity for implementing it to real world problems.
\end{abstract}

\section{Keywords-}

8/6 SRM, DSP (TMS320F2812), Sensorless Scheme, Fuzzy Estimator.

\section{INTRODUCTION}

Switched Reluctance Motors have gained momentum in the highly competitive market of adjustable speed motor drives. Simple structure and low cost are the most important reasons for this popularity. SRM drives have made a successful entrance into various sectors of industry such as aerospace, automotive, and home appliances. Its simple construction, due to the absence of magnets, rotor conductors, brushes improve system efficiency over a wide speed range make the SRM drive an interesting alternative to other commercially available drives [1]-[3].

The accurate knowledge of the rotor position is required for good performance of the switched reluctance motor drive. The entrance of SRMs in the sensitive applications in industries has proved the need for highly reliable and fault tolerant rotor position sensing methods. The need for the rotor angle information in SRM has been traditionally satisfied by the use of some form of rotor position sensor [3]. Rotor position sensing is an integral part of SRM control because of the nature of reluctance torque production. In fact, excitations of the SRM phases need to be properly synchronized with the rotor position for effective control of speed, torque and torque pulsation. But it needs a mechanism to detect rotor position for correct operation [5], [8]. An encoder, resolver, or Hall shaft position sensors are usually employed to determine the rotor position. However, these discrete position sensors not only add complexity and cost to the system but also tend to reduce the reliability of the drive system [4]. However, in recent years, there have been extensive research activities to eliminate direct rotor position sensors, simply by indirectly determining the rotor position. To avoid additional cost, size and unreliability associated with the external position sensors, developing a reliable, precise, and low-cost position sensorless control seem necessary [6].

Several sensorless control methods and patented have been reported in literature in the last decade. The various methods suggested have their own merits and demerits depending on their principles of operation. In order to come up with a technique to completely detect the rotor positions for the switched reluctance motor drives in all regions or modes of operation [7]. Ideally, it is desirable to have a sensorless scheme which uses only terminal measurements and does not require additional hardware. The main idea for rotor position detection is to use the relationship between the rotor position, the phase current, and the flux linkage [11]. The SRM is modeled by equations based on some parameters such as flux, current and torque, speed, and inductance, some of the parameters may obtain directly from the measurement of SRMs but some are undetermined. There are some intelligent control methods based on fuzzy control that has found applications in the detection of the rotor position in switched reluctance motors [12]-[13].

Authors use the concept of fuzzy logic for rotor position estimation in sensorless control of SRM drive. Furthermore, a major advantage of using a fuzzy logic that it can cope with inherent uncertainty in the input signals. Fuzzy systems can deal with situations where sharp distinctions between the boundaries of application of rules do not occur [14]. However, fuzzy logic does not need a complex mathematical model and, thus, has the advantage of relatively simple mathematical calculations used for the rule processing. In addition, it has been shown that the fastest possible universal computation scheme corresponds exactly to the operations in fuzzy logic methods using Max-Min composition [15]. Therefore, in terms of real-time sensorless SRM operation, it could be said that fuzzy logic techniques represent an ideal choice in some reasonable sense.

The fuzzy rules are developed from operators experience or experimental data. The fuzzy model encapsulates the nonlinear function relating the SRM rotor position to the flux linkage and current [2]-[3]. The model is then utilized during the operation of the sensorless rotor position estimation scheme to calculate the rotor position from measured values of flux linkage and current. In this mode of operation, the fuzzy model is essentially used as a nonlinear mapping of flux linkage and current to angle, based on the fuzzy rule base [16]. 
Section II explains the principle of operation of the proposed fuzzy logic based sensorless control scheme for SRM drive. Modelling of SRM proposed scheme is presented in Section III. The experimental verification of the proposed technique is explained in Section IV. In Section V, the results and discussions attribute of the proposed sensorless scheme are presented. Section VI summarizes and concludes the paper.

\section{PRINCIPLE OF OPERATION OF THE PROPOSED SRM SENSORLESS SCHEME}

The fundamental principle of operation of a SRM is based on the variation in flux linkage with the change in the angular position of the rotor. The proposed sensorless scheme relies on the fuzzy based rotor position estimator model of the SRM drive. The dynamics of the SRM drive can be represented by a set of non-linear first-order differential equations. The block diagram of the proposed sensorless scheme is shown in Fig. 1. It consists of various sub-systems necessary for PID speed controlled SRM drive with fuzzy logic use as a rotor position estimator. The flux estimator produced flux linkage by using phase voltage and current as inputs. The experimental data of flux linkage and phase current are used as inputs to fuzzy estimator and map them in fuzzy rule base for estimating the angle as an output. The suitable type of low pass filter has been used to produce refined estimated angle for inverter operation and simultaneously used to obtain estimated speed for comparison. This fuzzy based sensorless scheme is being simulated in MATLAB/Simulink environment. The simulated results have been compared with experimental results to verify the ability of this scheme for practicability.

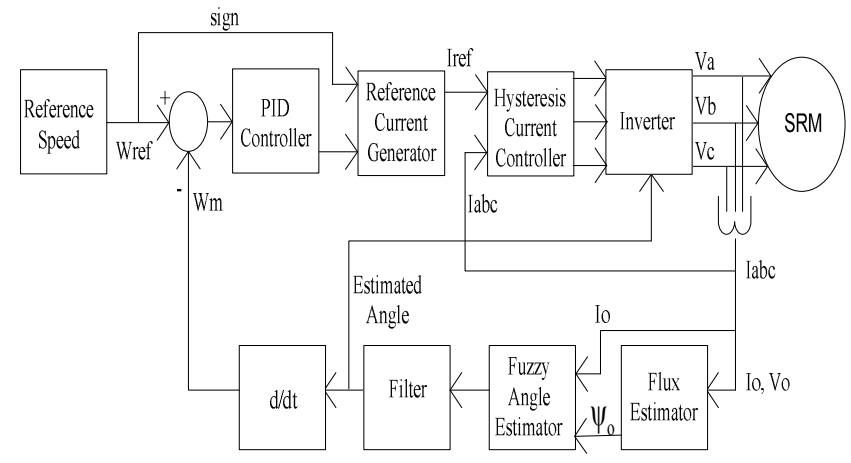

Fig. 1.Sensorless Control of SRM with Fuzzy Rotor Position Estimator

\section{MODELING OF SRM DRIVE PROPOSED SCHEME}

Different parts of the close-loop SRM drive system are modelled separately, which are then integrated to get the complete model. The drive system is divided into following sub-systems:

\subsection{Modeling of Switched Reluctance Motor}

Switched reluctance motor is highly nonlinear in nature, the instantaneous voltage across the terminal of a phase of a SR motor is governed by
$V=R I+\frac{d \varphi}{d t}$

The electromechanical equations governing the motor behaviour are

$\frac{d \omega}{d t}=\left(T_{e}-T_{l}\right) / J$

$T_{e}=\frac{d \omega}{d \theta}$

$\frac{d \theta}{d t}=\omega$

where $\omega=$ Supply frequency in $\mathrm{red} / \mathrm{sec}, I=$ Motor armature current, $R=$ Armature resistance, $\varphi=$ Armature inductance, $V=$ Voltage input to the motor, $T_{e}=$ Electrical torque, $J=$ Moment of inertia, $T_{L}=$ Load torque, $\theta=$ Rotor position

The experimentally obtained flux-current characteristic with the variation in angle is shown in Fig. 2. Similarly the torque-angle characteristics with angle are shown in Fig. 3. These characteristic is used to get the flux linkage and the final model is developed on the concept of energy and co-energy.

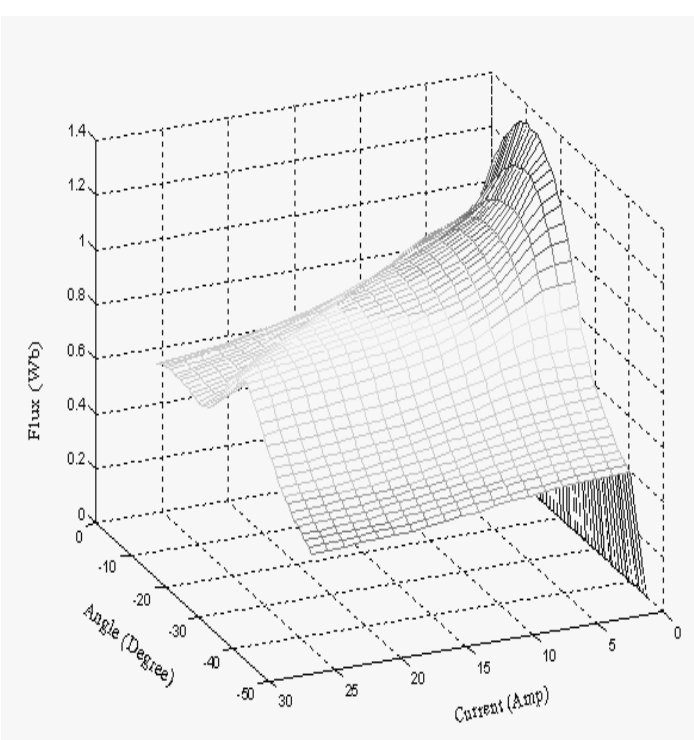

Fig. 2. Experimental flux- current characteristics 


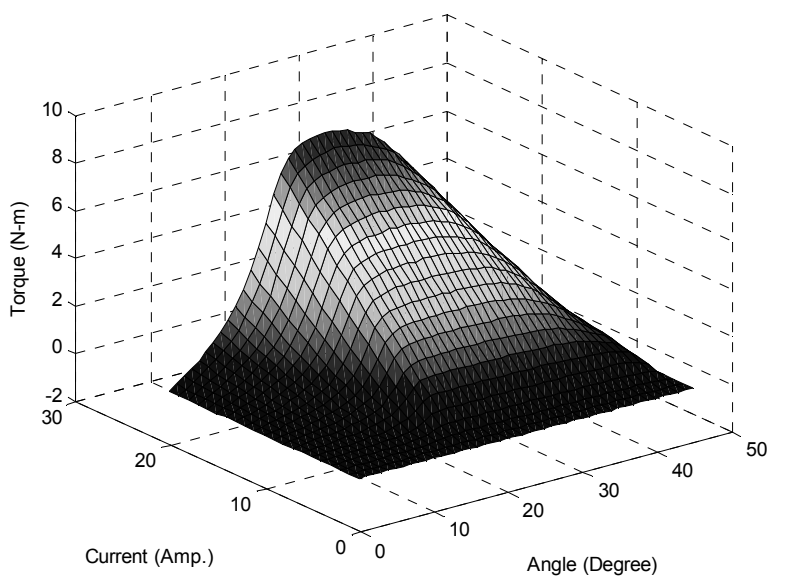

Fig. 3. Experimental torque- angle characteristics

\subsection{Modeling of PID Controller}

The discrete time equivalent expression for PID control used in this paper is given as

$u(k)=K_{b} e(k)+K_{i} T_{s} \sum_{i=1}^{n} e(k)+\frac{K_{d}}{T_{s}} \Delta e(k)$

Here, $\mathrm{u}(\mathrm{k})$ is the control signal, $\mathrm{e}(\mathrm{k})$ is the error between the reference and the process output, $\mathrm{T}_{\mathrm{s}}$ is the sampling period for the controller, and

$\Delta e(k) \equiv e(k)-e(k-1)$

The parameters of the PID controller $\mathrm{K}_{\mathrm{p}}, \mathrm{K}_{\mathrm{i}}$, and $\mathrm{K}_{\mathrm{d}}$ can be manipulated to produce various response.

\subsection{Hysteresis Current Controlled Inverter}

In the hysteresis current control current remain in the hysteresis band. To apply the voltages $+\mathrm{V}$ or zero depends upon the current error positive or negative. With regards to the rotor angle inverter output is as follow:

$$
\begin{gathered}
\text { If } \theta>=\theta_{\text {on }} \text { and } \theta<\theta_{\text {off }} \\
V_{\text {out }}=S^{*} V \\
\text { If } \theta>=\theta_{\text {off }} \text { and } \theta<\theta_{q} \\
V_{\text {out }}=-V \\
\text { If } \theta>\theta_{q} \\
V_{\text {out }}=0
\end{gathered}
$$

where $\mathrm{S}=$ switching of HCC, $\theta_{\text {on }}=$ turned on Phase excitation and $\theta_{\text {off }}=$ turned off phase excitation

It is seen that both angles are such that they occur in the rising inductance profile region so that positive torque is produced to move the rotor in the forward direction. Similar pattern can be written for the other phases.

\subsection{Flux Linkage Estimation}

The flux linkage estimator plays an important role for rotor position estimation. The quantity flux is generated by flux linkage estimator block, which calculates flux linkage based on the phase voltage and current in the active phase winding. The flux-linkage of any phase is computed by using Faraday's law from

$\psi=\int(V-I R) d t$

The calculation of flux linkages by equation (10), helpful in computing estimated angle for the operation of sensorless SRM drive.

\subsection{Modeling of Fuzzy Angle Estimator}

To create a fuzzy rotor position estimator model for SRM, the SRM magnetization curve (Flux linkage-current-rotor position) termed a fuzzy rule base. The magnetization data for several rotor positions are stored in fuzzy rule-base tables, the position information is retrieved from rule base tables during operation. This rule base is used to provide a value of rotor position from the inputs of the fuzzy model. The generated fuzzy rule base defines a function for mapping input values of flux linkage and current to output value of rotor position in term of angle.The theory was introduced long back ago, but recently its applications have received large momentum [14]. A variable in fuzzy logic has sets of values, which are characterized by linguistic labels, such as SMALL, MEDIUM, and LARGE etc. These labels are represented numerically by fuzzy sets. Each set is again characterized by membership function varies from 0 to 1 . Thus fuzzy sets can be viewed as mathematical representation of linguistic values. The numerical interval that is relevant for the description of fuzzy variables is commonly named as universe of discourse. A fuzzy set has a special feature of allowing partial membership. Crisp value or real value can either be or not be part of the set but it is member of a fuzzy set, with a degree of membership varying from 0 (non-member) to 1 (full member). Fuzzy logic system can be simply represented into four parts: the fuzzifier, the rule base, the interference engine and the defuzzifier [16].

During simulation estimated angle is compared with measured angle produces angle error and then fuzzy rule base has been updated accordingly to obtained negligible error means our scheme is trained properly for performing those applications for which it has been trained. The block diagram of fuzzy angle estimator scheme is shown in Fig. 4.

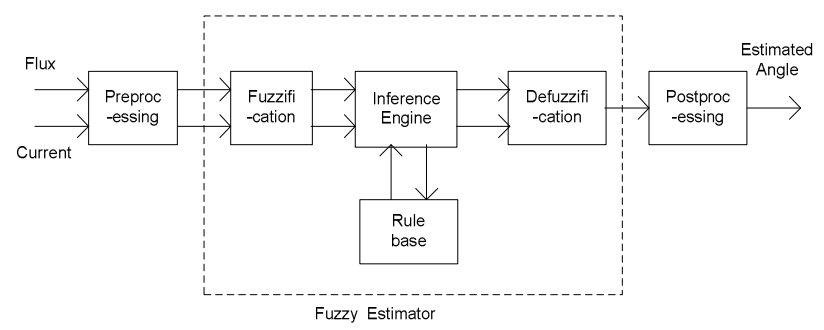

Fig. 4. Block Diagram of Fuzzy Angle Estimator Scheme

\section{(i) Fuzzifier}

Fuzzifier as shown in Fig. 4 is the first unit converts crisp value into fuzzy values using input membership functions and gains. The process is known as fuzzification. Different membership functions shapes can be used to convert crisp value to fuzzy value [7]. The preprocessing block is used to convert input signals within required range for processing.

\section{(ii) Inference Engine}

The inference engine uses the rule base and infers proper control 
action. A fuzzy rule typically has an IF-THEN format as follows:

IF ( $\mathrm{x}$ is A AND $\mathrm{y}$ is $\mathrm{B}$ ) THEN ( $\mathrm{z}$ is $\mathrm{C}$ )

where $\mathrm{x}, \mathrm{y}$ and $\mathrm{z}$ are fuzzy variables and $\mathrm{A}, \mathrm{B}$ and $\mathrm{C}$ are fuzzy subsets in the universe of discourses $\mathrm{X}, \mathrm{Y}$ and $\mathrm{Z}$ respectively. If the conditions in the antecedent are met, then the actions in the consequent are taken.

\section{(iii) Defuzzifier}

The fuzzy control action is again mapped into crisp value by defuzzifier. The process of conversion is known as defuzzification. Several defuzzification methods are available. The choice of method had been made depending upon computational burden and accuracy. This paper has used the center of gravity method for defuzzification:

$$
z_{o}=\frac{\int_{w} z C(z) d z}{\int_{w} C(z) d z}
$$

The calculation of the Center-of-Area defuzzified value is simplified if we consider finite universe of discourse $W$ and thus discrete membership function $C(\mathrm{z})$. Defuzzification process has been executed by using equation (8). Output has been process properly by postprocessing block to convert it in required range. Fuzzy rules and reasoning are utilized on-line to determine the estimator parameters based on error signal and its first difference. Efforts have been devoted to develop methods to reduce the time spent on optimizing the choice of estimator parameters. Parameters are normalized into the per unit values so that range can be defined between 0 and 1 . In the proposed scheme, estimator parameters are determined based on current and flux. The value of angle is determined by a set of fuzzy methods [17], [18].

\section{(iv) Represent Inputs and Output Domain in Fuzzy Resigns}

The ranges of intervals of the input and output variable domains are defined. In this case, the input domains are flux linkage and current are defined to have a domain of $0-1 \mathrm{~Wb}$ and $0-20 \mathrm{~A}$ respectively. Similarly, the domain of the angle is defined as $0-30$ degrees, as this is the electrical cycle for the motor used. Each domain is then divided up into fuzzy regions are normalized into the per unit values so that range can be defined between 0 and 1 , which is shown in Fig. 5. The variable spaces of flux linkage, phase current have been divided into 20 regions and 32 regions for rotor angle. The choice of the number of regions is a compromise between the numbers of resultant rules that are generated in the rule base. Each region is assigned a fuzzy membership function. In this work, the fuzzy sets were chosen to be isosceles triangular shapes, and the maximum point of each triangle was chosen to lie at the centre of its respective region. The other two vertices of the triangle are chosen to lie at the centres of the two neighbouring fuzzy regions, and at these two points the membership values were made zero [14]-[15].
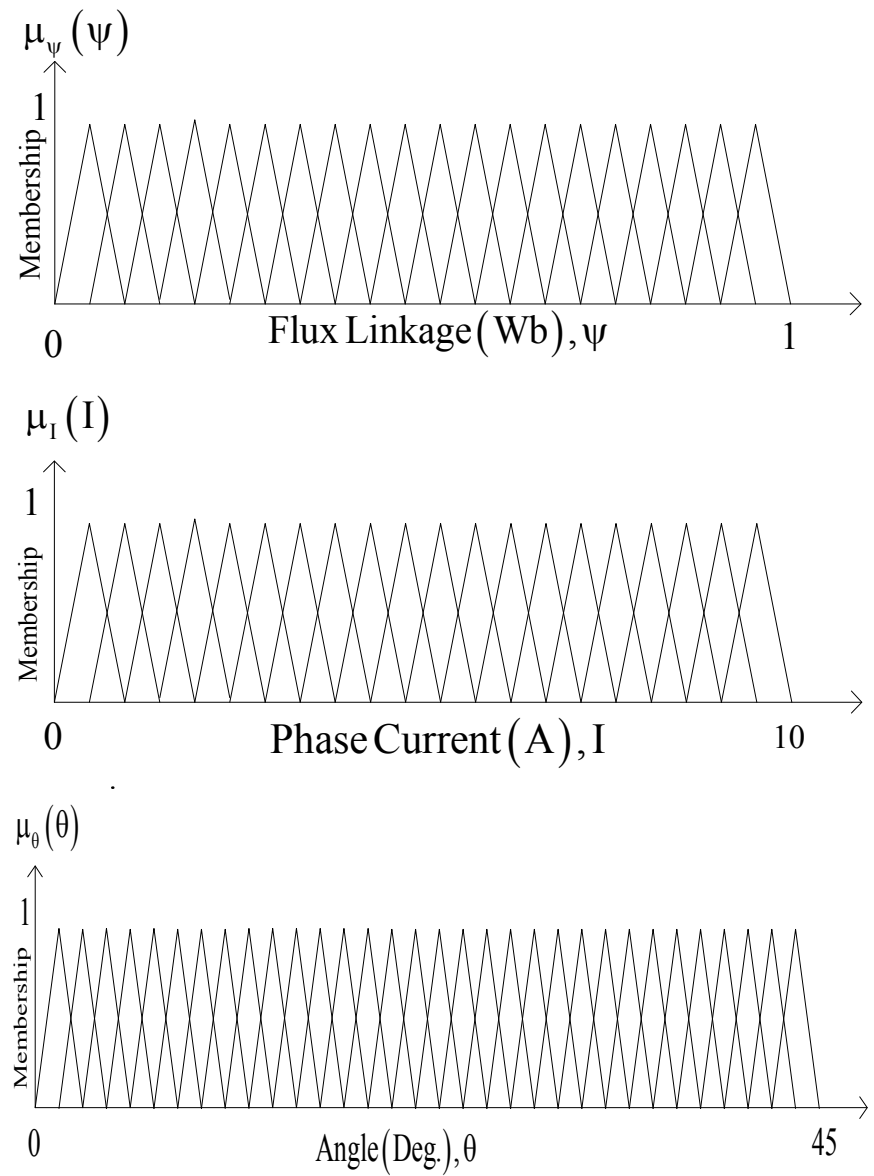

Fig. 5. Membership functions for $\Psi$, I and $\theta$

When each new rule is generated from the input-output data pairs, a rule degree or truth is assigned to that rule, where this rule degree is defined as the degree of confidence that the rule does, in fact, correlate to the function relating flux linkages and current to angle. Rule base for the sensorless scheme is made according to the number of inputs and their respective output. The rule base of fuzzy controller has been designed using flux linkage (20) and phase current (20) as inputs and angle in term of (32) output [19], [21].

\section{EXPERIMENTAL VERIFICATION OF THE PROPOSED TECHNIQUE}

The experimental setup consists of a DSP controlled four phase SRM drive system is made up of several distinct subsystems includes DSP development tool board (TMS320F2812), Code Composer Studio, Personal Computer, H-bridge converter, Hall current sensors, DC operated eddy current load (brake) and 8/6 pole SRM. This setup has been used for obtaining experimental results. The block diagram of experimental setup and photograph of DSP controlled SRM drive is shown in Fig. 6. and Fig. 7. 


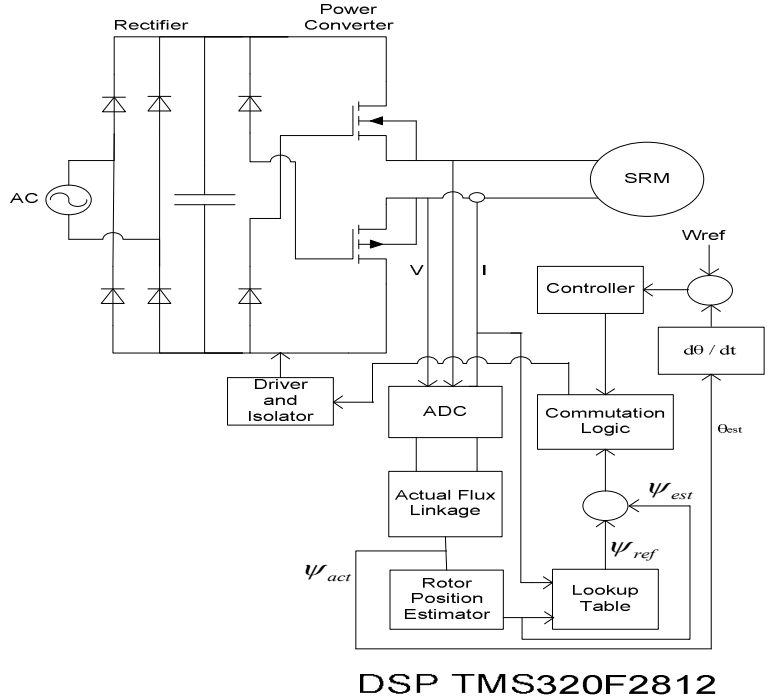

Fig. 6. Block diagram of DSP controlled SRM drive

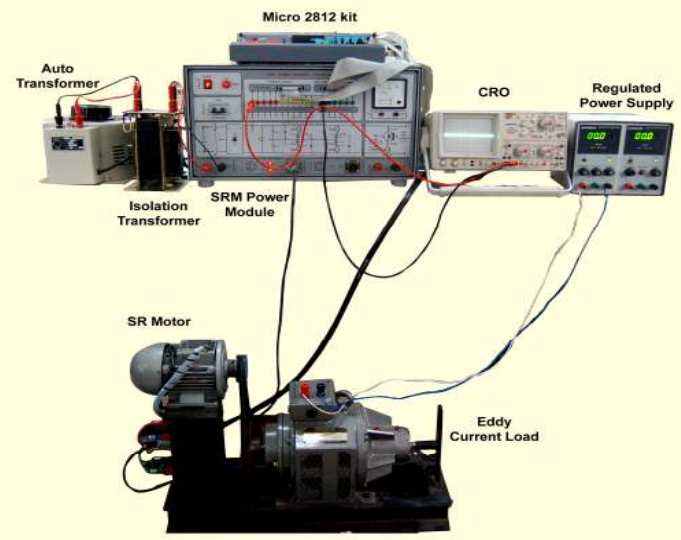

Fig. 7. Photograph of experimental setup of DSP controlled SRM drive

\section{RESULTS AND DISCUSSIONS}

The simulated and experimental results of SRM drive are discussed in this section. The results prove that the proposed fuzzy based sensorless scheme is estimating the rotor position with a low error. The results also reveal a transient error in the estimation of speed as the motor accelerates, which is shown in Fig. 8.1 and 8.5 but immediately settle down with reference speed. Simulation and experimental results show the validity of the proposed sensorless control of SRM drive. Simulated and experimental results have been verified successfully at low and high speed operations.

\section{A. Simulation Results of PID Speed Controlled Sensorless SRM Drive with Fuzzy Estimator}

The simulation results obtained in MATLAB environment at low $500 \mathrm{rpm}$ and high $4000 \mathrm{rpm}$ speed operation with phase current, phase voltage and angle are shown in Fig. 8.1- 8.8. The estimated angle is very close to actual one, which produce very low angle error over entire simulation period from 0.0 to $0.5 \mathrm{sec}$ is shown in Fig. 8.4 and
8.8. The phase current is higher at $4000 \mathrm{rpm}$ compared to $500 \mathrm{rpm}$, which is shown in Fig. 8.2 and 8.6. The phase voltage is low at high speed and high at low speed operation.

\section{i. Performance of sensorless scheme at low speed $=500 \mathrm{rpm}$}

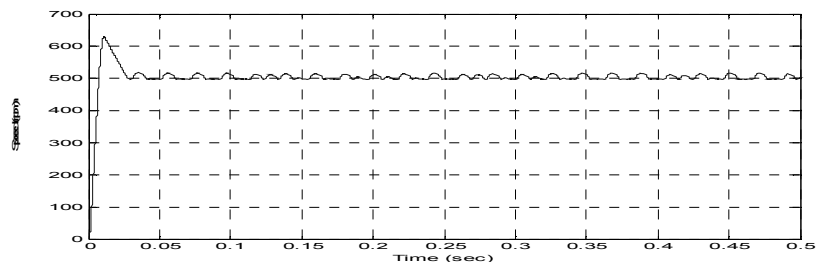

Fig. 8.1. Rotor speed vs. time

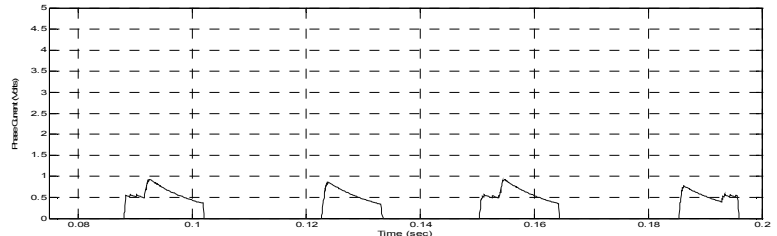

Fig. 8.2. Phase current vs time

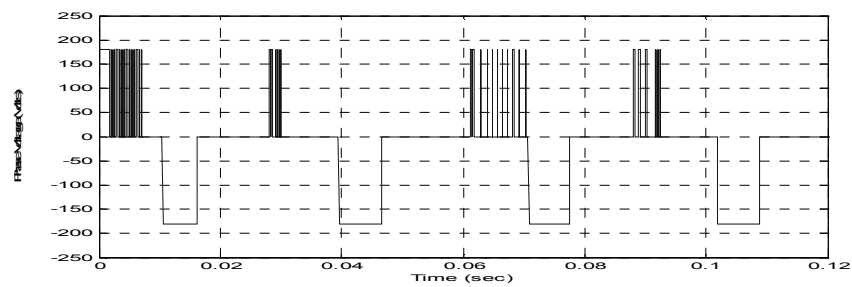

Fig. 8.3. Phase voltage vs. time
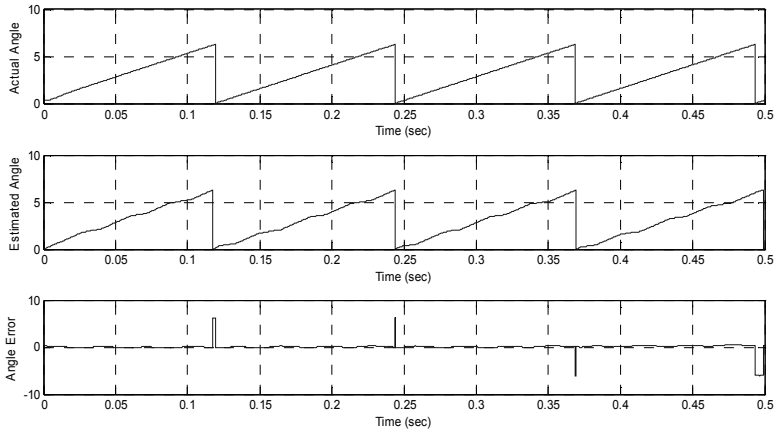

Fig. 8.4. Actual Angle vs. time

\section{ii. Performance of sensorless scheme at high} speed $=4000 \mathrm{rpm}$

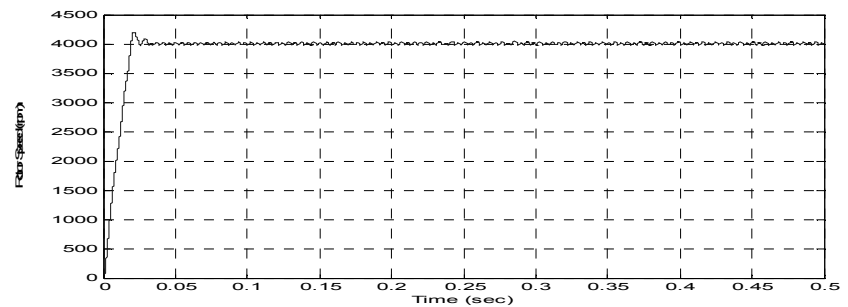

Fig. 8.5. Rotor speed vs. time 


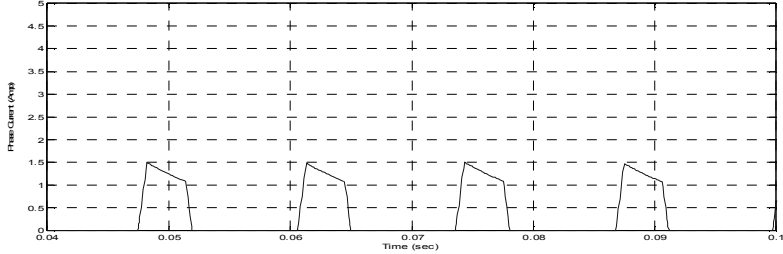

Fig. 8.6. Phase current vs time

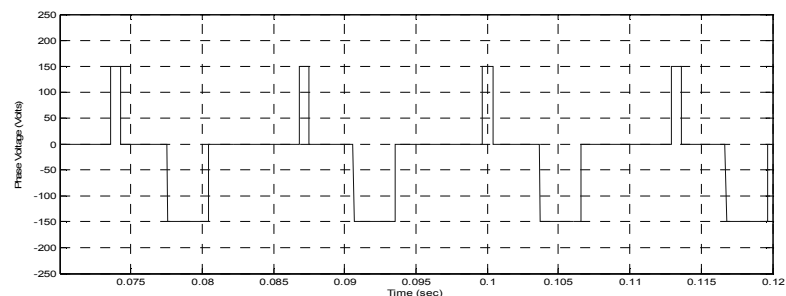

Fig. 8.7. Phase voltage vs. time
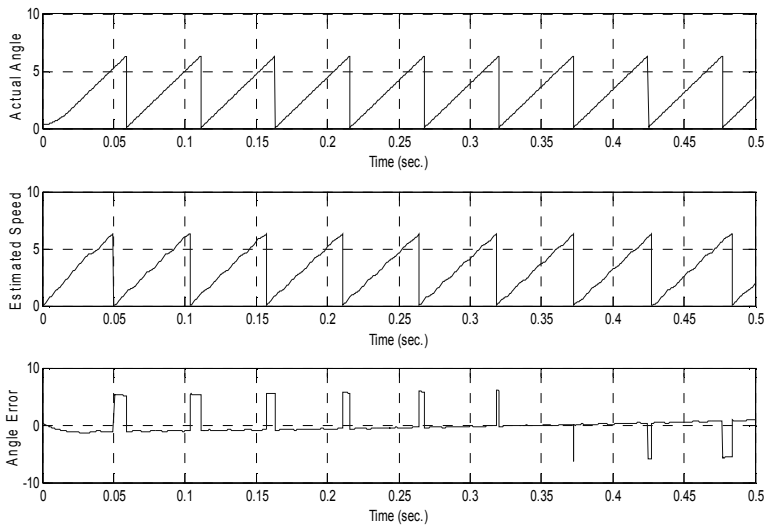

Fig. 8.8 Angle vs time

\section{B. Experimental Results of DSP Controlled SRM Drive}

The experimental results of rotor speed, phase current phase voltage and rotor angle are shown in this section. The experimental system is designed with the TMS320F2812 DSP controlling overall operation of the SRM drive. The performance of DSP controlled SRM drive at low speed $500 \mathrm{rpm}$ and at high speed $4000 \mathrm{rpm}$ with phase voltage, Phase current and angle are shown in Fig. 9.1-9.10. The estimated angle and actual angle plot are very close to each other in both conditions of operation with small angle error.

\section{i. Performance of DSP Controlled at low speed = 500 rpm}

$\mathrm{Ws}=$ set speed, $\mathrm{Wm}=$ measured speed

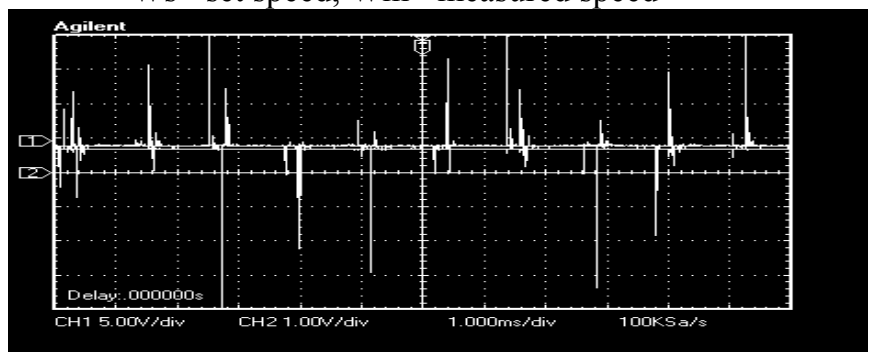

Fig. 9.1. Rotor speed vs. time

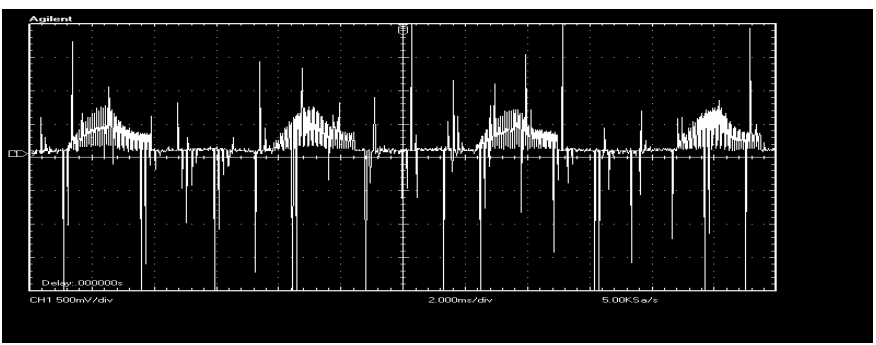

Fig. 9.2. Phase current vs. time

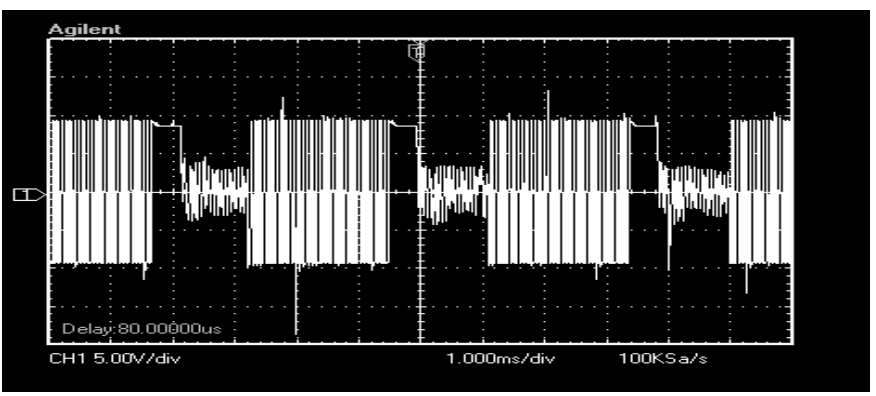

Fig. 9.3. Phase voltage vs. time

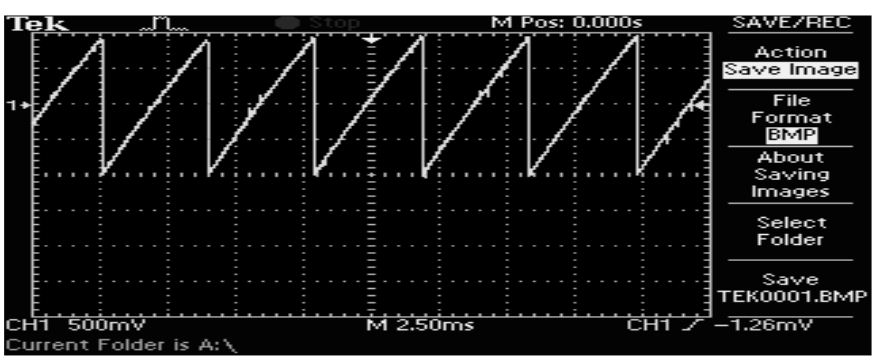

Fig. 9.4. Actual Angle vs. time

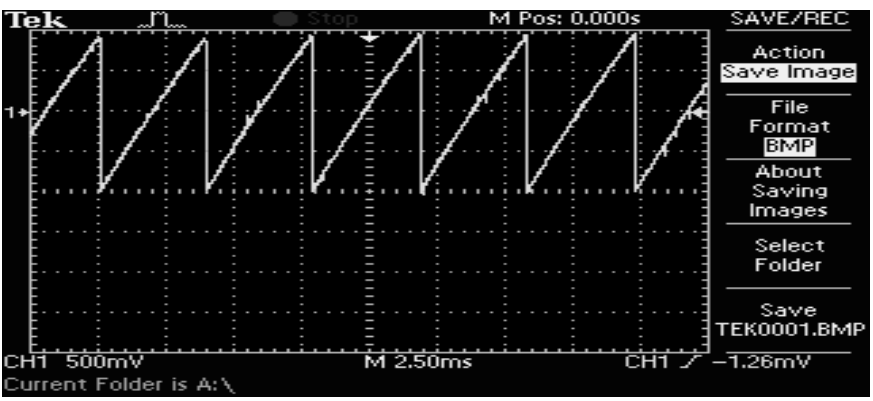

Fig. 9.5. Estimated Angle vs. time

ii. Performance of DSP Controlled at high speed $=4000 \mathrm{rpm}$

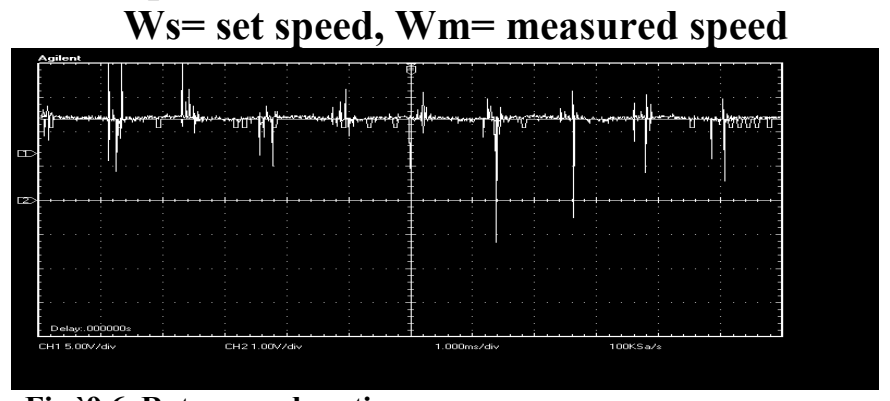

Fig. 9.6. Rotor speed vs. time 


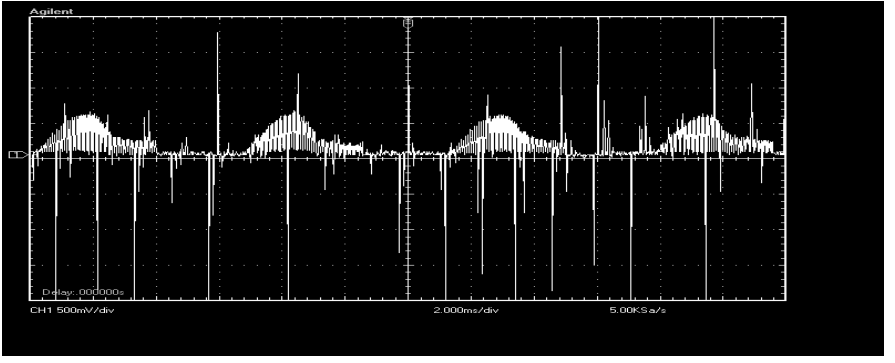

Fig. 9.7. Phase current vs. time

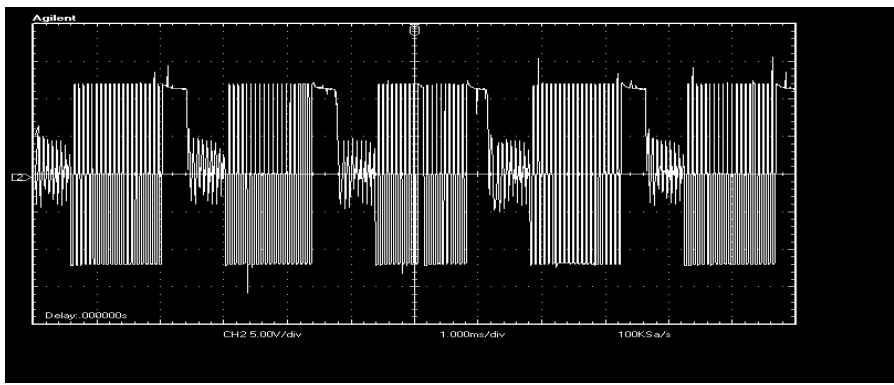

Fig. 9.8. Phase voltage vs. time

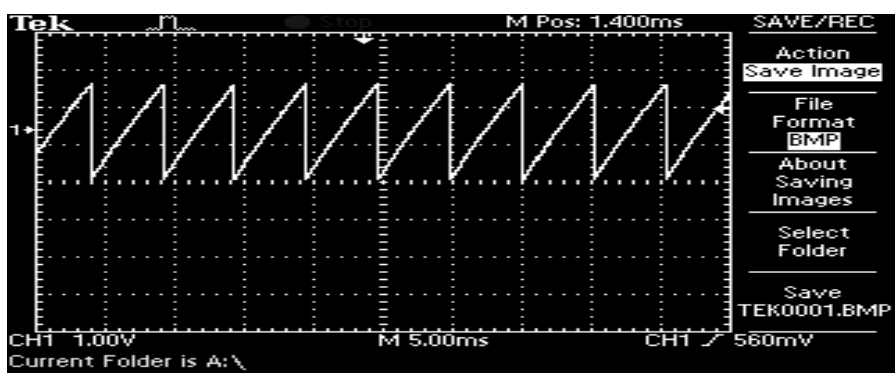

Fig. 9.9. Actual Angle vs. time

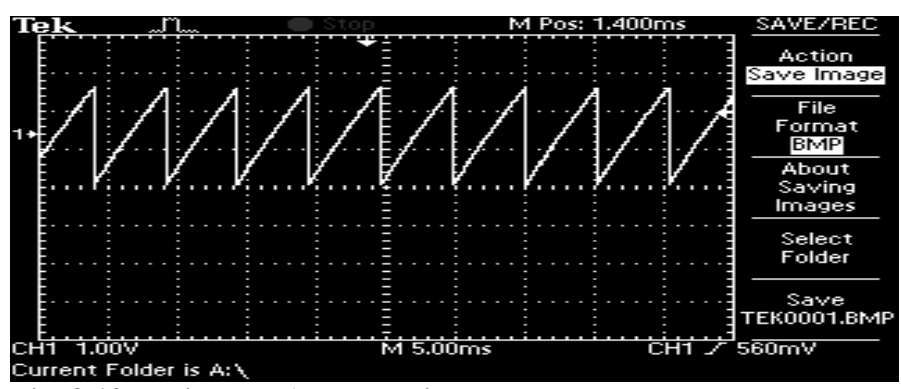

Fig. 9.10. Estimated Angle vs. time

\section{CONCLUSIONS}

This paper proposes an approach for sensorless rotor position estimation in SRM drive. A novel fuzzy logic based rotor position estimation technique is explained and simulated, which provides an alternative way of measuring the rotor position in SRM drive. The main advantage of fuzzy estimator is that it can be tuned and adapted if necessary, thus enhancing the degree of freedom of control. The simulated results have verified that the sensorless controlled of SRM drive with fuzzy estimator scheme can successfully and vigorously predict the rotor angle very close to the experimental results under different operating conditions. We have drawn conclusion that fuzzy based sensorless control of SRM drive is suitable for real world problems, because its results are matched with experimental results for same drive specifications.

\section{APPENDIX}

DC bus voltage: $300 \mathrm{~V}$, Rated Power: $0.75 \mathrm{kw}$, Base speed: 8000 rpm; No. of stator poles: 8; No. of rotor poles: 6; No. of phases: 4; Stator pole arc: 20.39degree; Rotor pole arc: 21.6 degree; Unaligned phase inductance: $8.623 \mathrm{mH}$; Aligned phase inductance: $53.3 \mathrm{mH}$; Phase resistance (R): $1.3 \mathrm{ohms}$; Inertial co-efficient (J): $.0013 ; \theta_{\text {on }}: 0^{\circ} ; \theta_{\text {off }}: 40^{\circ} ; \theta_{q}: 60^{\circ}$, Current: 2.5A, DC Operated Eddy Current Load (Brake)

\section{REFERENCES}

[1] Buju G. S., Menis Roberto and Valla Maria. J, "Variable Structure Control of an SRM Drives", IEEE Trans. on Ind. Electron., Vol. 1, Feb 1993, pp 56-63.

[2] R. Krishnan, "Switched Reluctance Motor Drives: Modelling, Simulation, Analysis, Design, and Applications", CRC Press, 2001.

[3] T. J. E. Miller. "Electronic control of switched reluctance motors". Newnes Power Engineering Series Oxford, UK, 2001.

[4] TMS320F2812 Datasheet, Texas Instruments, 2002.

[5] F.Soares, P.J.Costa Branco, "Simulation of a 6/4 Switched Reluctance Motor Based on Matlab/Simulink Environment," IEEE Trans. on Aerospace and Electronic System, vol. 37, no. 3, pp. 989-1009, July 2001.

[6] G. Baoming and Z. Nan, "DSP- based Discrete-Time Reaching Law Control of Switched Reluctance Motor", IEEE International conference IPEMC, 2006, pp. 1-5.

[7] G. Gallegos-Lopez, P. C. Kjaer, and T. J. E. Miller, "High-grade position estimation for SRM drives using flux linkage/current correction model," IEEE Trans. Ind. Appl., vol. 35, no. 4, pp. 859-869, Jul./Aug. 1999.

[8] Ramasamy G., Rajandran R.V., Sahoo N.C., "Modeling of Switched Reluctance Motor drive System using Matlab/Simulink for Performance Analysis of Current Controllers", IEEE PEDS, 2005, pp. 892-897.

[9] R. Kumar, R. A. Gupta and S. K. Bishnoi, "Converter Topologies for Switched Reluctance Motor Drives", International Review of Electrical Engineering, Vol. 3, No. 2 , March-April 2008, pp. 289-299.

[10] Mehrdad Eshani, Iqbal Husain, Sailendra Mahajan and K. R. Ramani, "New Modulation Encoding Techniques for Indirect Position Sensing in Switched Reluctance Motors", IEEE Trans. Industry Appl., Vol. 30, No. 1, January/February 1994, pp. 85-91.

[11] J. Bu and L. Xu, "Eliminating starting hesitation for reliable sensorless control of switched reluctance motors," IEEE Trans. Ind. Appl., vol. 37, no. 1, pp. 59-66, Jan./Feb. 2001.

[12] Mehrdad Eshani, Iqbal Husain and Ashok B. Kulkarni, "Elimination of Discrete Position Sensor and Current Sensor in Switched Reluctance Motor Drives", IEEE Trans. Industry Appl., Vol. 28, No. 1, January/February 1992, pp. 128-135.

[13] Hongwei Gao, Salmasi, F.R., Ehsani, M., "Inductance modelbased sensorless control of the switched reluctance motor drive at low speed," IEEE Trans. On Power Electron., Vol. 19, Issue 6, pp. 1568-1573, Nov. 2004.

[14] Gilberto C. D. Sousa, B. K. Bose,” A Fuzzy Set Theory Based Control of a Phase Controlled Converter DC Machine Drive", Trans. on Industry Appl., Vol.30, No.1, Jan.1994.

[15] Adrian Cheok and Nesimi Ertugrul, "High Robustness and Reliability of a Fuzzy Logic Based Angle Estimation Algorithm 
for Practical Switched Reluctance Motor Drives", IEEE International Conference, 1998, pp. 1302-1308.

[16] Adrian D. Cheok and Nesimi Ertugrul, "Use of Fuzzy Logic for Modeling, Estimation, and Prediction in Switched Reluctance Motor Drives", IEEE Trans. on Ind. Electron., Vol. 46, No. 6, December, 1999, pp. 1207-1224.

[17] Rajesh Kumar, R. A. Gupta, Sachin Goyal and S.K.Bishnoi, "Fuzzy Tuned PID Controller Based PFC Converter-Inverter Fed SRM Drive", IEEE International Conference Ind. Technology, December 15-17, 2006, pp.2498-2503.

[18] M. Ehsani and B. Fahimi, "Elimination of position sensors in switched reluctance motor: State of the art and future trends," IEEE Trans. Ind. Electron., vol. 49, no. 1, pp. 40-47, Feb. 2002.

[19] P. Acarnley and J. Watson, "Review of position-sensorless operation of brushless permanent-magnet machines," IEEE Trans. Ind. Electron., vol. 53, no. 2, pp. 352-362, 2006.
[20] D. S. Reay and B. W. Williams, "Sensorless position detection using neural networks for the control of switched reluctance motors," in Proc. IEEE Int. Conf. Control Appl., Aug. 1999, vol. 2, pp. 1073-1077.

[21] E. Mese and D. A. Torrey, “An Approach for Sensorless position estimation for Switched Reluctance Motors using artificial neural networks," IEEE Trans. Power Electron., vol. 17, no. 1, pp. 6675, Jan. 2002.

[22] R. Krishnan, S. Park, and K. Ha, "Theory and operation of a fourquadrant switched reluctance motor drive with a single controllable switch-The lowest cost four-quadrant brushless motor drive," IEEE Trans. Ind. Appl., vol. 41, no. 4, pp. 10471055, Jul./Aug. 2005. 